\title{
Low-Power Ion Propulsion for Small Spacecraft
}

Michael J. Patterson

Lewis Research Center, Cleveland, Ohio

Steven R. Oleson

NYMA, Inc., Brook Park, Ohio

Prepared for the

33rd Joint Propulsion Conference and Exhibit cosponsored by AIAA, ASME, SAE, and ASEE

Seattle, Washington, July 6-9, 1997

National Aeronautics and

Space Administration

Lewis Research Center 
Available from

NASA Center for Aerospace Information 800 Elkridge Landing Road

Linthicum Heights, MD 21090-2934

Price Code: A03
National Technical Information Service 5287 Port Royal Road Springfield, VA 22100 


\title{
Low-Power Ion Propulsion for Small Spacecraft
}

\author{
Michael J. Patterson* \\ National Aeronautics and Space Administration \\ Lewis Research Center \\ Cleveland, Ohio \\ Steven R. Oleson \\ NYMA, Inc. \\ NASA Lewis Research Center Group \\ Brook Park, Ohio
}

\begin{abstract}
Analyses were conducted which indicate that sub $\mathrm{kW}$-class ion thrusters may provide performance benefits for near-Earth space commercial and science missions. Small spacecraft applications with masses ranging from 50 to $500 \mathrm{~kg}$ and power levels less than $0.5 \mathrm{~kW}$ were considered. To demonstrate the efficacy of propulsion systems of this class, two potential missions were chosen as examples; a geosynchronous north-south station keeping application, and an Earth orbit $m$ agnetospheric mapping satellite constellation. Xenon ion propulsion system solutions using small thrusters were evaluated for these missions. A payload mass increase of more than $15 \%$ is provided by a $300-W$ ion system for the north-south station keeping mission. A launch vehicle reduction from four to one results from using the ion thruster for the magnetospheric mapping mission. Typical projected thruster performance over the input power envelope of $100-300 \mathrm{~W}$ range from approximately $40 \%$ to $54 \%$ efficiency and approximately 2000 to 3000 seconds specific impulse. Thruster technologies required to achieve the mission-required performance and lifetime are identified.
\end{abstract}

\section{Introduction}

Analyses are ongoing to examine ion thruster scaling relationships in detail to determine system requirements, performance limits, and lifetime expectations. Specifically, electron-bombardment xenon ion thruster solutions are being evaluated for input power levels of several hundred watts. Solutions examined include thruster sizes ranging from about six to $10 \mathrm{~cm}$ in beam diameter, at input power levels in the range of $0.1-0.3$ $\mathrm{kW}$. The performance, design, and lifetime goals for this engine class are identified in Table $I$.

The impacts of low-power ion propulsion systems on commercial and science missions were considered. This was done to investigate the relative benefits of developing flight systems based on low power ion thrusters for application on small spacecraft.

North-South station keeping (NSSK) on a small $(430 \mathrm{~kg}$ ) geostationary satellite was considered as one target mission for low-power ion technology. A constellation of four 65-kilogram magnetospheric mapping spacecraft with a mission consisting of an orbit transfer from LEO to GEO was also chosen to investigate the viability of the small ion propulsion for small spacecraft.

This paper discusses these two mission applications, the benefits of, and technology requirements for low power

\footnotetext{
${ }^{*}$ Aerospace Engineer, Member AIAA
}

ion propulsion as applied to small spacecraft for these commercial and science missions.

\section{Propulsion System}

This section describes elements of the low power ion propulsion system used in this study including thruster, power processor, and propellant feed system.

\section{Thruster}

Estimates for low-power electron bombardment xenon ion thruster operation were calculated for use in the mission analyses. The methodology and results are discussed here.

Performance - For purposes of this analysis, input power levels from about $100 \mathrm{~W}$ to a maximum of about $300 \mathrm{~W}$ input power into the thruster were assumed. Thruster configurations ranging from about $6 \mathrm{~cm}$ to $10 \mathrm{~cm}$ beam diameters were initially examined for this power range, with a final selection of $8 . \mathrm{cm}$ (beam diameter) for this study. The considerations driving the thruster size selection included: the maximum acceptable beam current density, which impacts grid life time; the minimum discharge electrical efficiency which impacts overall thruster efficiency; and the maximum acceptable operating discharge voltage which impacts both discharge chamber and screen grid lifetime. 
An 8-cm thruster operating at $200 \mathrm{~W}$ input power, and at comparable grid voltages to the $30-\mathrm{cm}$ NSTAR thruster, will operate at about the same average current density as the NSTAR thruster (approximately $2.9 \mathrm{~mA} / \mathrm{cm}^{2}$ ).

Hence, one would anticipate comparable accelerator grid lifetimes at this condition.

At about 3000 seconds specific impulse and at the maximum input power of $300 \mathrm{~W}$, the beam current density of an $8 \mathrm{~cm}$ is about $4.1 \mathrm{~mA} / \mathrm{cm}^{2}$, or about 1.4 times that of the NSTAR thruster. As will be discussed in a following section, this increase in current density, while maintaining useful thruster lifetimes, is considered feasible.

In general, as total propellant throughput decreases, the discharge electrical efficiency also decreases. That is, the power to produce an ampere of beam ion current increases as the thruster is power-throttled down. ${ }^{1}$ This is because the neutral density in the discharge decreases and, hence, the probability that energetic electrons will undergo inelastic collisions prior to being collected at anode surfaces decreases.

Because the primary electron containment length decreases as the beam diameter is reduced, the discharge electrical efficiency also decreases. To maintain a constant propellant efficiency the discharge must be operated at successively higher voltages as the thruster diameter is decreased. ${ }^{2}$ Restated, if fewer electrons are available to ionize the gas (due to the higher loss rate of primary electrons), their mean energy has to increase to maintain a constant ionization rate.

For a beam diameter of $8 \mathrm{~cm}$, very high discharge voltages $(>32 \mathrm{~V})$ are required to attain discharge propellant efficiencies of $90 \%$ or greater. ${ }^{2}$ Here, a clear trade exists in thruster efficiency versus life time, in the trade of maximum propellant efficiency versus maximum discharge voltage.

For this analysis, it was assumed that the thruster would be operated at a maximum discharge voltage of $28 \mathrm{~V}$ at full power, to ensure adequate life time. This is consistent with past design criteria, including that used in the development of the NSTAR $30 \mathrm{~cm}$ thruster. A linear increase in discharge propellant efficiency with input power is expected, and propellant efficiencies ranging from about $78 \%$ at $100 \mathrm{~W}$ to about $82 \%$ at $300 \mathrm{~W}$ were assumed.

The discharge losses were estimated using a correlation established between discharge losses and thruster input power. ${ }^{\prime}$ At an input power of $100 \mathrm{~W}$, discharge losses of
$333 \mathrm{~W} / \mathrm{A}$ were estimated; at $300 \mathrm{~W}$ thruster input power, 266 W/A was assumed.

The ion optics performance for the 8-cm thruster was scaled from that demonstrated with 2 -grid $30 \mathrm{~cm}$ optics. For this analysis, the perveance documented for the small-hole-accelerator-grid (SHAG) ion optics from reference 3 was used. For these optics, the beam current (in amperes) was found to be approximately $4.8 \times 10^{-}$ ${ }^{5}(\mathrm{Vt})^{1.5}$, where $\mathrm{Vt}$ is the total accelerating voltage in volts.

Adjusting for the difference in beam area, the perveancelimited beam current for the $8 \mathrm{~cm}$ using SHAG optics ranged from about $57 \mathrm{~mA}$ to about $204 \mathrm{~mA}$, over a range of $600 \mathrm{~V}$ to $1400 \mathrm{~V}$ total voltage. This total voltage range is approximately equal to that which is used for the NSTAR thruster. For performance estimations, the accelerator grid voltage was calculated assuming an Rratio of 0.80 , and the accelerator grid current was assumed to be equal to $0.50 \%$ of the beam current over the entire power-throttling range.

A hollow cathode with keeper was assumed to provide the beam neutralization. A fixed keeper current of 100 $\mathrm{mA}$ (yielding a conservative 3:1 total emission current ratio with/without beam extraction) at $20 \mathrm{~V}$ keeper voltage and $15 \mathrm{~V}$ coupling voltage was assumed. Applying an empirically-derived correlation of flow rates to emission current, a maximum flow rate of $36 \mathrm{eq}$. $\mathrm{mA}$ xenon (about $0.49 \mathrm{sccm}$ ) was estimated for the neutralizer.

Using the aforementioned assumptions regarding discharge chamber, ion optics, and neutralizer operation, performance estimates for an 8-cm thruster were obtained over an input power range of about $100 \mathrm{~W}$ to $300 \mathrm{~W}$. These estimates are shown in Table II, and in Figures 1 and 2. Thrust losses associated with beam divergence and doubly-charged ions were accounted for in these estimates, using the methodology described in reference 3.

As indicated in Figure 1 and Table II, estimates of thruster efficiency range from about $37 \%$ at 1810 seconds specific impulse and $85 \mathrm{~W}$ input power, to about $54 \%$ at 2960 seconds and $300 \mathrm{~W}$ input power. These performance values are believed to be reasonable goals based on testing conducted to date.

A critical area necessary to achieve the goals and performance levels identified in Tables I and II is development of low-flow rate xenon hollow cathodes. The hollow cathode neutralizer performance has a significant impact on overall thruster efficiency at $100-300 \mathrm{~W}$ thruster 
power levels. A program to develop efficient, low flow cathodes to support low-power electric propulsion systems is in progress. The performance of one of the first units is shown in Figure 3, a plot of minimum xenon flow rate (to maintain stable spot-mode operation) versus emission current.

Also shown in Figure 3 are data obtained from the NSTAR thruster neutralizer, and the projected (assumed) neutralizer performance used in this analysis. As indicated, the prototype neutralizer operates at approximately 7-8 times lower flow rate for the same emission current, compared to the NSTAR neutralizer. However, additional improvements (factor of 2 reduction in flow rate and emission current) are needed to achieve the performance assumed in this analysis.

At $100 \mathrm{~W}$ thruster input power the hollow cathode neutralizer operation can degrade the thruster efficiency and specific impulse by as much as 20 percentage-points and 2000 seconds, respectively, as indicated in Figure 4. In Figure 4, projected thruster performance is given for three cases; a zero-flow rate/zero power-consuming neutralizer, a $0.05 \mathrm{sccm}$ flow rate neutralizer (operating at the same input power as that of the $0.50 \mathrm{sccm}$ neutralizer used in this analysis), and the baseline 0.50 sccm neutralizer. The performance of the $0.05 \mathrm{sccm}$ flow rate neutralizer is comparable to that which was demonstrated previously on an $8 \mathrm{~cm}$ mercury ion thruster. $^{4}$

Note for the $0.50 \mathrm{sccm}$ neutralizer curve, the thruster efficiency decreases with increasing specific impulse.

This is because at fixed thruster input power a direct trade of beam current for beam voltage is made, for increasing specific impulse. This results in a very rapid decrease in the maximum obtainable propellant efficiency, since the fixed neutralizer flow rate of 0.50 sccm becomes a larger fraction of the total thruster flow rate.

Lifetime - For the NASA NSTAR $30 \mathrm{~cm}$ thruster, the erosion of the molybdenum accelerator grid due to charge-exchange ions is one of the dominant life limiting wear-mechanisms. If the internal discharge voltage of a small thruster is limited to $28 \mathrm{~V}$ to limit internal erosion, then charge-exchange erosion of the accelerator grid is expected to be the overall life limiter.

Examinations of accelerator grid erosion on many different ion thrusters have led to a consensus that the end-of-life of an accelerator grid will be determined by structural failure in the center of the grid where the erosion is the greatest. In particular, erosion occurs around each grid hole as deep pits which are connected together by shallower trenches. ${ }^{5}$ Erosion in the trenches is a minimum between adjacent charge-exchange pits.

After significant erosion occurs, each grid hole is bridged to its neighbors at these minimum erosion sites. ${ }^{6}$ End-oflife of the accelerator grid is thereby defined as the point in time at which these bridges in the center of the grid become unsound and fail.

The relevant local measurement for this accelerator grid end-of-life mechanism is the bridge depth erosion in the grid center. A compilation of the magnitude of accelerator grid erosion experienced during extendedduration tests along with the thruster operating conditions were documented in reference 7 . Using these data, a "grid erosion parameter" (or GEP) was proposed (consisting of the product of the accelerator grid impingement current, test time, and grid material sputter yield, divided by the beam area) as a straightforward combination of measured parameters with a high correlation to the magnitude of the charge exchange erosion. ${ }^{7}$ The NSTAR lifetest results to date suggest that this approach yields a conservative erosion estimate.

Using the GEP, the accelerator grid lifetime of the NSTAR thruster at $2.3 \mathrm{~kW}$ was estimated to be greater than 12,000 hours. ${ }^{7}$ This estimate was supported by subsequent post-life test erosion measurements which indicated the grid lifetime was in fact in excess of 12,000 hours. ${ }^{8,9}$ The NSTAR thruster lifetime is conservativelyquoted as having a total propellant throughput of $83 \mathrm{~kg}$, which is the propellant expended at a full-power level of $2.3 \mathrm{~kW}$ for 8000 hours.

The 8-cm thruster should yield comparable life times to that of the NSTAR thruster when operated at similar voltages and current densities. At equivalent full-power conditions and assuming comparable optics technology, the small thruster should have at least a $10-\mathrm{kg}$ throughput capability.

Using the GEP, estimates of small thruster life times were obtained for the conditions identified in Table II.

These data are shown in Figure 5, thruster (accelerator grid) life versus thruster input power. For these calculations, 2-grid molybdenum ion optics was assumed with an initial accelerator grid thickness of 500 microns.

Two curves are shown in Figure 5 corresponding to two different end-of-life criteria. One criterion is erosion of the bridge to a depth of 200 microns, or $40 \%$ of the way through the thickness of the electrode. This is presently used in the NSTAR program as a conservative definition of end-of-life. This is quite conservative as the grid still 
has considerable strength at this erosion level. A second curve is shown in Figure 5, corresponding to a bridge erosion to a depth of 400 microns, or $80 \%$ of the way through the thickness of the electrode. In a test-tofailure-test ${ }^{6}$ the accelerator grid electrode was eroded to this depth and it was still functional at the completion of the test. As indicated in Figure 5, lifetimes of $\geq 8000$ hours are anticipated for input power levels up to $300 \mathrm{~W}$ assuming 400 microns erosion.

Figure 5 indicates that using the conservative NSTAR end-of-life criterion for accelerator grid erosion may result in thruster lifetimes less than $\mathbf{8 0 0 0}$ hours for input power levels greater than about $180 \mathrm{~W}$. At the $300 \mathrm{~W}$ power level assumed for the proposed missions, the anticipated life is about 4000 hours. Approaches to enhancing accelerator grid and thruster life are available and these include: changing to a three-grid configuration; application of sputter-resistant coatings to the molybdenum accelerator grid surface; or changing to a carbon-based grid material.

Other approaches to increased life include limiting the maximum power to the $8-\mathrm{cm}$ thruster to a value less than $300 \mathrm{~W}$, or increasing the thruster size at $300 \mathrm{~W}$ input. For example, an increase in thruster diameter to $10 \mathrm{~cm}$ would be expected to yield at least a $50 \%$ increase in grid life.

The thruster total impulse versus input power is shown in Figure 6 for both end-of-life criteria. As indicated, total impulse values ranging from $9.6 \times 10^{5} \mathrm{~N}$-s down to about $3.1 \times 10^{5} \mathrm{~N}$-s are estimated over the power envelope of 85 $\mathrm{W}$ to $300 \mathrm{~W}$, assuming 400 microns erosion.

Physical Characteristics - A $0.30 \mathrm{~kW}$ class electrostatic thruster could implement similar design, materials and fabrication techniques as those employed in the $30-\mathrm{cm}$ NSTAR engineering model ion thruster. ${ }^{10}$ These include a partial-conic anode-potential discharge chamber constructed of non-ferromagnetic materials, ${ }^{10}$ and a ringcusp magnetic circuit."

The fabrication techniques and material used in the NSTAR thruster allow for very lightweight thrusters to be built. For example, the $30-\mathrm{cm}$ NSTAR thruster mass is about half that of other engineering model and flight model thrusters of this approximate size. ${ }^{12}$ Using this same approach, an $8-\mathrm{cm}$ flight thruster mass of $0.775 \mathrm{~kg}$ is estimated.

The overall thruster length, as measured from the tip of the neutralizer, to the rearmost portion of the plasma screen, is estimated to be about $17.6 \mathrm{~cm}$. The outside diameter of the thruster, as defined by a circle which includes the neutralizer assembly, is estimated to be 16.7 $\mathrm{cm}$.

\section{Power Processing}

The power processor unit (PPU) mass for the ion thruster is estimated to be approximately $2.0 \mathrm{~kg}$, at about $300 \mathrm{~W}$ maximum. ${ }^{13}$ A PPU topology similar to that implemented in the NSTAR program, with the input bus voltage of 2432 volts was also assumed. ${ }^{13}$ The efficiency of the PPU is assumed to vary linearly with input power, going from about 0.87 to 0.89 over an input power range of $100 \mathrm{~W}$ to $300 \mathrm{~W}^{14}$

\section{Propellant Feed System and Structure}

The tankage in the systems considered is set at $10 \%$ of the propellant mass. ${ }^{15}$ A gimbal mass equal to $34 \%$ of the thruster mass, and a structure mass equal to $31 \%$ of the combined thruster, gimbal, and feed system masses, are assumed. ${ }^{16}$ Additional mounting structure of $4 \%$ of the PPU, propellant, and tankage are also assumed. ${ }^{17} \mathrm{~A}$ thermal radiator mass equal to $31 \mathrm{~kg} / \mathrm{kW}$-dissipated was also assumed. ${ }^{16}$

\section{Mission Analyses}

To investigate the relative benefits of developing flight systems based on the $0.30 \mathrm{~kW}$ class ion thruster, two mission examples were considered. The first is NorthSouth station keeping (NSSK) of a small (430 kg) geostationary satellite since smaller geostationary satellites designed to serve one customer or provide a single service are currently being considered. ${ }^{17}$

The second mission example is a $65-\mathrm{kg}$ magnetospheric mapping spacecraft. This mission consists of an orbit raise from LEO to GEO to investigate the viability of the small ion propulsion for small science spacecraft. The ion propulsion system component masses used in both mission examples were based on the information presented above. A potential propulsion system configuration was also suggested. Each mission application compared the ion propulsion system to SOA propulsion systems. In both cases, a substantial mass savings was demonstrated as a result of using the ion thruster propulsion system, which could then be allocated to increase the usable payload mass. Conversely, if the baseline payload remained unchanged, the total spacecraft mass and launch mass could be reduced through the use of the ion system.

\section{Small Geostationary Satellite}

Large geostationary satellites continue to be an important part of the communication industry. Smaller geostationary satellites designed to serve one customer or 
provide a single service is also being considered. One such example is the planned Indostar 1 spacecraft, shown in Figure $7 .^{18}$ With a beginning-of-life (BOL) mass of 430 kilograms and an end-of-life (EOL) power of 0.9 kilowatts, the Indostar 1 is significantly smaller than other planned geostationary satellites.

Using the Indostar 1 as representative of this new class of satellites, the impact of the ion thrusters on reducing the wet system mass was estimated. Reduction in propulsion system wet mass would allow for an increase in the mass of the payload and support systems, a reduction in launch mass, or an increase in the spacecraft life. A 10-year mission with a $45 \mathrm{~m} / \mathrm{s}$ NSSK budget per year is assumed. $^{19}$ State-of-art $\mathrm{N}_{2} \mathrm{H}_{4}$ monopropellant ${ }^{20}$ and advanced arcjet systems ${ }^{21}$ were used for comparison. The operating parameters and system masses assumed are shown in Table III.

The configuration assumed for the ion and arcjet systems consists of four thrusters, two each on the north and south faces of the satellite and two PPUs. To minimize the effect of plume impingement on the solar arrays the ion thrusters were canted at 301 relative to the optimal thrust direction along the north-south axis and the arcjets were canted at 171. 22.23 Two thrusters are operated at a time. Burns are at one of the orbit nodes once per day, although less periodic burns are possible depending on the orbit inclination tolerance required. The electric thrusters run off of the eclipse batteries while the payload uses the solar array power. ${ }^{23}$ While the added cycling may require extra batteries to ensure 10 year payload eclipse operations, this was not included in the analysis.

Each of the electric propulsion systems requires lifetimes less than those currently predicted. For the ion system the two thrusters fire for approximately 45 minutes once a day. For the arcjet system, each of the two thrusters fires for approximately 11 minutes once a day, although longer burns, less often might be tolerated. Slightly longer burns may also be needed to reduce requirements during eclipse period.

The required propellant and propulsion system dry masses are shown in Figure 8. As indicated, all of the system dry masses were below 20 kilograms. However the differences in propulsion system wet masses were significant. The hydrazine monopropellant system was the heaviest, with a fueled mass of 92 kilograms. The arcjet system has a wet mass of 58 kilograms. The SOA ion system has a wet mass of only 23 kilograms. The approximate $75 \%$ reduction in propulsion system wet mass for the ion system relative to the hydrazine monopropellant propulsion system, corresponds to a 69- kilogram mass savings on a 430-kilogram spacecraft. This extra mass could be used for more communications payload along with the support systems required.

\section{Magnetospheric Mapping Constellation}

In this mission, four spacecraft would spiral in a constellation from $600 \mathrm{~km}$ to $36,000 \mathrm{~km}$ at a 65 / inclination for over a year to obtain spatial data of the Earth=s magnetosphere. This multi-spacecraft mission will allow for continuous spiral exploration of a portion of the magnetosphere and revisits of regions of interest. The four identical spacecraft provide redundancy; two of the four spacecraft could fail and still some spatial data could be attained.

The Orbital Sciences Corporation (OSC) MicroStar bus ${ }^{24}$ (shown in Figure 9) was selected as the bus for comparison of the $300 \mathrm{~W}$ ion and SOA bipropellant chemical propulsion system performance. MicroStar is a 50-100 kg class satellite with a dry bus mass of $\sim 40 \mathrm{~kg}$ and a typical payload of $\sim 50 \mathrm{~kg}$. This spacecraft structure is a $0.981 \mathrm{~m}$ diameter $\mathrm{x} 0.114 \mathrm{~m}$ deep ring providing a disc-shaped region which contains the bus subsystems (e.g. the batteries, electronics, and propulsion), as well as the payload. ${ }^{18,24,25}$

For this mission, each of the four spacecraft has either a single small ion system operating at $0.30 \mathrm{~kW}$, or a SOA bipropellant system for propulsion. The mission ${ }^{\text {a }} \mathrm{V}$ is $\sim 4700 \mathrm{~m} / \mathrm{s}$ for both the ion thruster and the chemical thruster since near-circular orbits are to be maintained throughout the mission. The analysis includes shading, degradation, and a $5 \%$ coast time during sunlit periods for the ion propelled spacecraft. The bipropellant spacecraft could take more data ans/or complete the mission faster due to the relatively-higher thrust of the propulsion system.

Using the $0.30 \mathrm{~kW}$ ion propulsion system, four spacecraft can be launched from a single Pegasus XL. A 570 day transfer is required to transfer the spacecraft to geosynchronous altitude. During the transfer the spacecraft arrays are degraded to about half the original power level due to the Van Allen radiation belt. The power into the thruster PPU drops from about $300 \mathrm{~W}$ at BOL to about $160 \mathrm{~W}$ by the end of the mission as shown in Figure 10. The propulsion system efficiency (product of the thruster and PPU efficiencies) and the specific impulse decay from about $48 \%$ at 2960 seconds to about $41 \%$ at 2440 seconds over this power range. The estimated payload is $10 \mathrm{~kg}$, with a total spacecraft launch mass of about $65 \mathrm{~kg}$. The science payload power was assumed to be $25 \mathrm{~W}$. 
To perform the same mission using the bipropellant engine would require a $300 \mathrm{~kg}$-class spacecraft, compared to the $65 \mathrm{~kg}$ ion propelled spacecraft. A comparison of the spacecraft launch mass for the ion propelled spacecraft versus the equivalent spacecraft using the 290-s bipropellant engine is shown in Figure 11. The fuel mass of the chemically-propelled spacecraft would be around $240 \mathrm{~kg}$. The trip times for the chemically-propelled spacecraft constellation are limited by the time to acquire the spatial data and not the thrusting time.

The $300 \mathrm{~kg}$ mass of the bipropellant spacecraft would require a dedicated Pegasus XL launch for each spacecraft. Thus the bipropellant spacecraft would require a total of four Pegasus $\mathrm{XL}$ launch vehicles as compared to the single Pegasus $\mathrm{XL}$ launch vehicle needed for the ion propelled spacecraft constellation. At around 12 million dollars a launch for the Pegasus $\mathrm{XL},{ }^{26}$ the small ion option could save this mission -36 million dollars in launch costs.

While the projected thruster lifetime at $300 \mathrm{~W}$ is adequate for the NSSK application, it falls considerably short of the 13,700 hours required for the magnetospheric mapping mission. This is mitigated however by the fact that the mission-average thruster input power is only about $200 \mathrm{~W}$. The total-impulse requirement for the mission is about $3.0 \times 10^{5} \mathrm{~N}$-s which appears feasible based on the data of Figure 6.

\section{Conclusions}

Analyses were conducted which indicate that sub 0.5 $\mathrm{kW}$-class ion thrusters may provide performance benefits for commercial and science missions. Small spacecraft applications with masses ranging from 50 to $500 \mathrm{~kg}$ and power levels less than $500 \mathrm{~W}$ were considered.

Electron-bombardment xenon ion thruster systems were evaluated for these missions. A low power system was postulated and system characteristics were estimated. Typical projected small thruster performance over the input power envelope of $100-300 \mathrm{~W}$ range from approximately $40 \%$ to $54 \%$ efficiency and approximately 2000 to 3000 seconds specific impulse.

Two potential mission applications for the ion thruster operating at $300 \mathrm{~W}$ (BOL) were identified including a geosynchronous north-south station keeping application, and an Earth orbit magnetospheric mapping satellite constellation. Impacts on launch vehicle requirements were quantified for both missions.
The geosynchronous north-south station keeping mission considered the use of the small $(430 \mathrm{~kg}$ ) Indostar 1 spacecraft, and a 10 -year mission with a $45 \mathrm{~m} / \mathrm{s}$ NSSK budget per year. Use of the $300 \mathrm{~W}$ ion system yielded an approximate $75 \%$ reduction in propulsion system wet mass relative to the hydrazine monopropellant propulsion system.

The Earth orbit magnetospheric mapping satellite constellation mission would use four Orbital Science Corporation (OSC) Microstar-class spacecraft, each propelled by a single $300 \mathrm{~W}$ throttleable ion engine. The combination of the OSC satellite bus, low power ion propulsion, and a Pegasus XL launch vehicle, allow for a spiral of the constellation from $600 \mathrm{~km}$ to $36,000 \mathrm{~km}$ at 65 degrees inclination in approximately 570 days. The use of the small ion thruster enables a single Pegasus XL launch of all four satellites; four Pegasus XI's would be required to perform the mission chemically.

Critical thruster technology areas necessary to achieve the mission-required performance and lifetimes include the development of low-flow rate xenon hollow cathodes, and high-current density long-life ion optics.

\section{References}

${ }^{1}$ Patterson, M.J. and Rawlin, V.K., "Derated Ion Thruster Design Issues," IEPC-91-150, October 1991.

${ }^{2}$ Patterson, M.J. and Foster, J.E., "Performance and Optimization of a 'Derated' Ion Thruster for Auxiliary Propulsion," AIAA-91-2350, June 1991.

${ }^{3}$ Patterson, M.J., "Low-Isp Derated Ion Thruster Operation," AIAA Paper No. 92-3203, July 1992.

${ }^{4}$ Power, J.L., "Planned Flight Test of a Mercury Ion Auxiliary Propulsion System - Objectives, System Descriptions, and Mission Operations," NASA TM78859, April 1978.

${ }^{5}$ Rawlin, V.K., "Erosion Characteristics of TwoGrid Ion Accelerating Systems," IEPC Paper No. 93-175, September 1993.

${ }^{6}$ Brophy, J.R., Polk, J.E., and Pless, L.C., "Testto-Failure of a Two-Grid, $30 \mathrm{~cm}$ dia. Ion Accelerator System," IEPC Paper No. 93-172, September 1993.

${ }^{7}$ Patterson, M.J., Haag, T.W., Rawlin, V.K., and Kussmaul, M.T., "NASA $30 \mathrm{~cm}$ Ion Thruster Development Status," AIAA Paper No. 94-2849, June 1994. (Also NASA TM-106842).

${ }^{8}$ Patterson, M.J., Rawlin, V.K., Sovey, J.S., and Kussmaul, M.T., " $2.3 \mathrm{~kW}$ Ion Thruster Wear Test," AIAA Paper No. 95-2516, July 1995. (Also NASA TM107076). 
${ }^{9}$ Polk, J.E., et. al., "A 1000-Hour Wear Test of the NASA NSTAR Ion Thruster," AIAA Paper No. 962717, July 1996.

${ }^{10}$ Patterson, M.J., Haag, T.W., and Hovan, S.A., "Performance of the NASA $30 \mathrm{~cm}$ Ion Thruster," IEPC Paper No. 93-108, September 1993. (Also NASA TM1064226)

${ }^{11}$ Sovey, J.S., "Improved Ion Containment Using a Ring-Cusp Ion Thruster," Journal of Spacecraft and Rockets, Vol. 21, Sept.-Oct. 1984, pp. 488-495.

${ }^{12}$ Hart, S.L., personal communication, April 1997.

${ }^{13}$ Pinero, L., personal communication, April 1997.

${ }^{14}$ Hamley, J., personal commumication, October 1996.

${ }^{15}$ Clauss, C.W., "Benefits of Low- Power Stationary Plasma Thruster Propulsion for Small Satellites," Proceedings of the 4th Annual Conference on Small Satellites, September 1995.

${ }^{16}$ Byers, D.C., Terdan, F.F., and Myers, I.T., "Primary Electric Propulsion for Future Space Missions," AIAA Paper No. 79-0881, May 1979.

${ }^{17}$ Manzella, D, et.al., "Evaluation of Low Power Hall Thruster Propulsion," AIAA Paper No. 96-2736, July 1996.

${ }^{18}$ Jane's Space Directory, Tenth Edition 19941995. Andrew Wilson Ed., Jane's Information Group Inc, Alexandria, VA, 1994.
${ }^{19}$ Agrawal, B.N., Design of Geosynchronous Spacecraft, Prentice-Hall, Inc., Englewood Cliffs, NJ, 1986.

${ }^{20}$ Myers, R.M., Oleson, S.R., Curran, F.M, and Schneider, S.J., "Small Satellite Propulsion Options," AIAA Paper No. 94-2997, June 1994.

${ }^{21}$ Lichon, P.G., McLean, C.H., Vaughn, C.E., and Sankovic, J.M., "Development of a 500 Watt Class Arcjet Thruster System," IEPC Paper No. 95-237, September 1995.

${ }^{22}$ Oleson, S.R., Myers, R.M., Kluever, C.A., Riehl, J.P., and Curran, F.M, "Advanced Propulsion for Geostationary Orbit Insertion and North-South Station Keeping," AIAA Paper No. 95-2513, July 1995.

${ }^{23}$ Free, B.A., "North-South Station keeping with Electric Propulsion Using Onboard Battery Power," COMSAT Laboratories, 1980.

${ }^{24}$ Meurer, Robert H., First Class Science On A Coach Class Ticket, Orbital Sciences Corporation, Dulles, Virginia 20166.

${ }^{25}$ Steffy, David A., ORBCOMM Satellites Launch and Initial Flight Operations, Orbital Sciences Corporation, Dulles, Virginia 20166.

${ }^{26}$ Isakovitz, S.J., International Reference Guide to Space Launch Systems, 2nd Ed., 1996, copyright 1991.

Table I - Low-Power Ion Thruster Goals

\begin{tabular}{|c|c|}
\hline Attribute & Value \\
\hline \hline Input Power, W & $200 \mathrm{~W}$ \\
\hline Efficiency & $246 \%$ \\
\hline Mass, kg & $1 \mathrm{~kg}$ \\
\hline Life Time & $8000 \mathrm{~h}$ \\
\hline
\end{tabular}


Table II - 8 cm Thruster Solutions ${ }^{\mathrm{a}}$

\begin{tabular}{|c|c|c|c|c|c|c|c|c|c|}
\hline $\begin{array}{c}\text { Input } \\
\text { Power, w }\end{array}$ & $\begin{array}{c}\text { Specific } \\
\text { Impulse, sec }\end{array}$ & $\begin{array}{c}\text { Thrust, } \\
\mathbf{m N}\end{array}$ & $\begin{array}{c}\text { Efficiency, } \\
\%\end{array}$ & $\begin{array}{c}\text { Beam } \\
\text { Current, mA }\end{array}$ & $\begin{array}{c}\text { Screen } \\
\text { Voltage, V }\end{array}$ & $\begin{array}{c}\text { Accel } \\
\text { Current, mA }\end{array}$ & $\begin{array}{c}\text { Accel } \\
\text { Voltage, }|\mathrm{V}|\end{array}$ & $\begin{array}{l}\text { Discharge } \\
\text { Current, A }\end{array}$ & $\begin{array}{c}\text { Discharge Flow } \\
\text { Rate, eq. } \mathrm{mA}\end{array}$ \\
\hline 85 & 1810 & 3.6 & 37.2 & 88.2 & 640 & 0.44 & 160 & 0.94 & 110 \\
\hline 99 & 2030 & 4.0 & 40.1 & $"$ & 800 & $"$ & 200 & $"$ & $"$ \\
\hline 113 & 2230 & 4.4 & 42.2 & $"$ & 960 & $"$ & 240 & $"$ & " \\
\hline 128 & 2410 & 4.8 & 43.9 & $"$ & 1120 & $"$ & 280 & $"$ & $"$ \\
\hline 138 & 2180 & 5.6 & 43.2 & 123 & 800 & 0.62 & 200 & 1.32 & 154 \\
\hline 158 & 2390 & 6.1 & 45.5 & $"$ & 960 & $"$ & 240 & $"$ & $"$ \\
\hline 177 & 2590 & 6.6 & 47.2 & $"$ & 1120 & " & 280 & $"$ & $"$ \\
\hline 187 & 2680 & 6.8 & 48.0 & $"$ & 1200 & " & 300 & $"$ & $"$ \\
\hline 207 & 2510 & 8.1 & 47.9 & 162 & 960 & 0.81 & 240 & 1.73 & 202 \\
\hline 233 & 2720 & 8.7 & 49.7 & $"$ & 1120 & $"$ & 280 & $"$ & " \\
\hline 246 & 2820 & 9.0 & 50.5 & $"$ & 1200 & $"$ & 300 & $"$ & $"$ \\
\hline 286 & 2860 & 10.9 & 53.6 & 204 & 1120 & 1.02 & 280 & 1.94 & 249 \\
\hline 303 & 2960 & 11.3 & 54.3 & $"$ & 1200 & $"$ & 300 & $"$ & $"$ \\
\hline
\end{tabular}

${ }^{2}$ Discharge voltage $=28 \mathrm{~V}$. Neutralizer parameters: $0.1 \mathrm{~A}$ keeper current, $20 \mathrm{~V}$ keeper voltage, $15 \mathrm{~V}$ coupling voltage, 36 eq. $\mathrm{mA}$ flow rate.

Table III - Propulsion System Comparison for a $430 \mathrm{~kg}$ Geostationary Satellite

\begin{tabular}{|c|c|c|c|}
\hline Propulsion System & $\mathrm{N}_{2} \mathrm{H}_{4}$ Monopropellant & $\mathrm{N}_{2} \mathrm{H}_{4}$ Arcjet & Xenon Ion \\
\hline Total Spacecraft mass, kilograms & 430 & 430 & 430 \\
\hline Propulsion Dry mass, kilograms & 11.1 & 14.4 & 14.9 \\
\hline Propellant mass, kilograms & 79.9 & 43.6 & 7.6 \\
\hline Propulsion Wet mass, kilograms & 92 & 58 & 23 \\
\hline System Power, Watts & $\mathrm{n} / \mathrm{a}$ & $2 @ 339$ (ea) & $2 @ 339$ (ea) \\
\hline$-\mathrm{V}, \mathrm{m} / \mathrm{s}$ & 450 & 450 & 450 \\
\hline Thruster Specific Impulse, sec & 223 & 450 & 2960 \\
\hline Gross Engine Thrust, Newtons & 4.45 & $2 @ 0.040(\mathrm{ea})$ & $2 @ 0.011(\mathrm{ea})$ \\
\hline \# of thrusters & 4 & 4 & 4 \\
\hline Cant Angle, degrees & 0 & 17 & 30 \\
\hline Total burn time, hours & 2.7 & 670 & 2700 \\
\hline Daily burn time, minutes & 0.04 & 11 & 45 \\
\hline
\end{tabular}




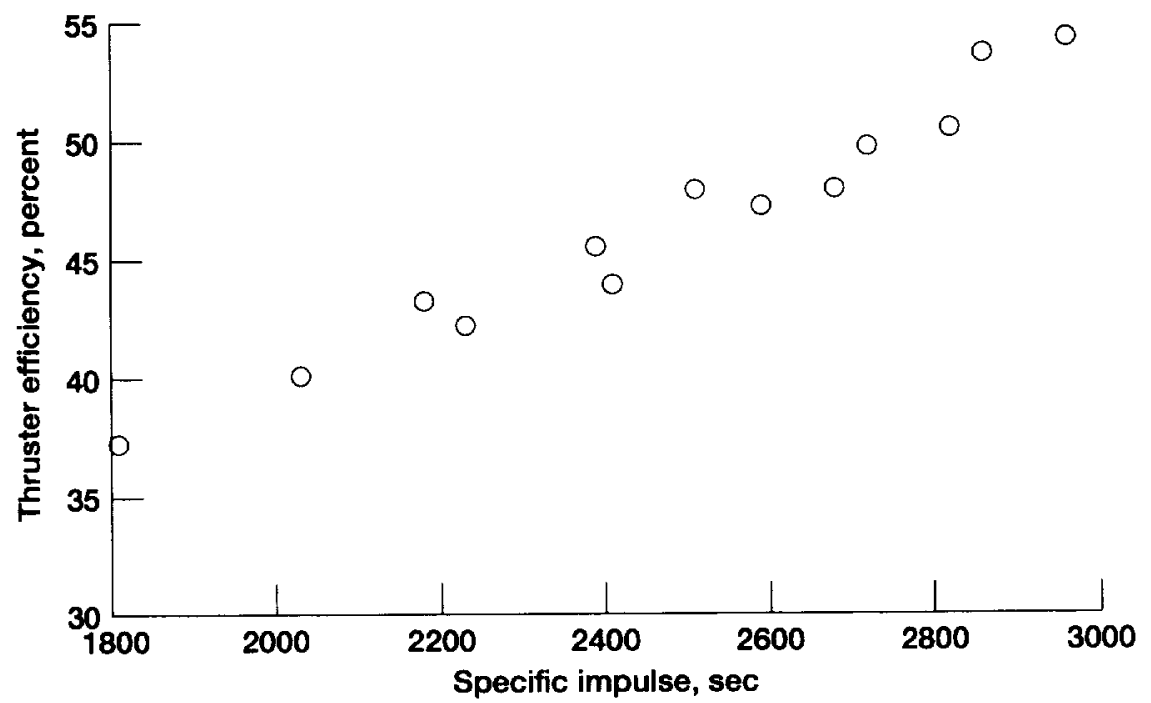

Figure 1.-Projected $8 \mathrm{~cm}$ thruster efficiency versus specific impulse.

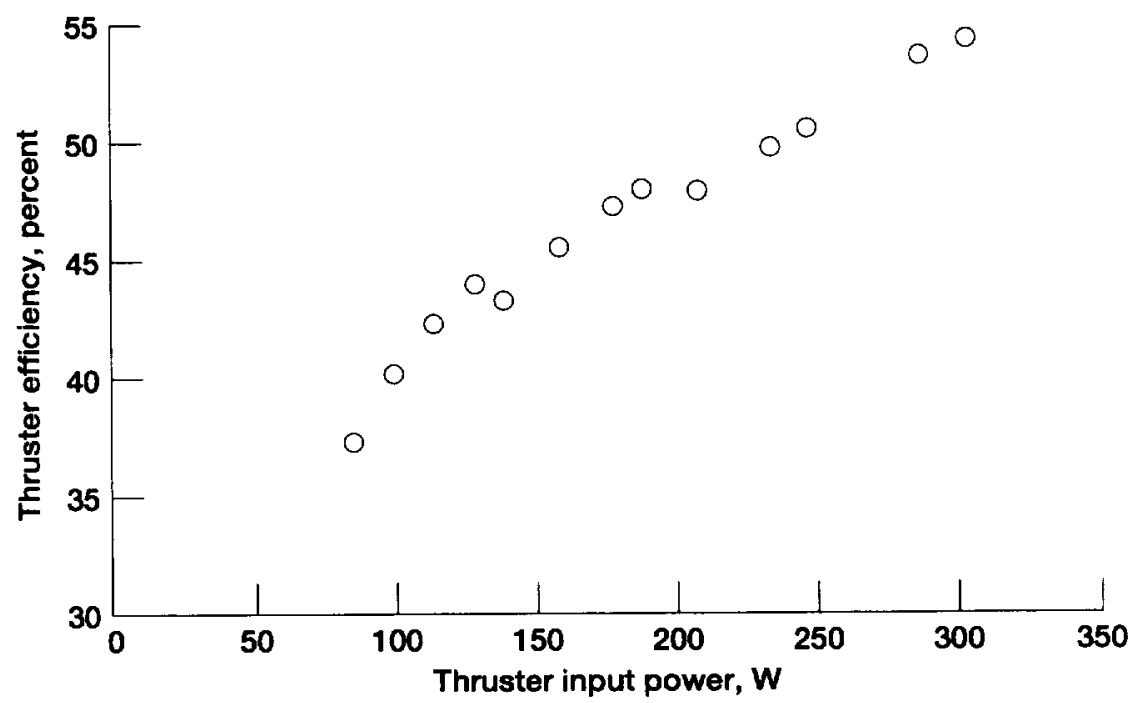

Figure 2.-Projected $8 \mathrm{~cm}$ thruster efficiency versus input power. 


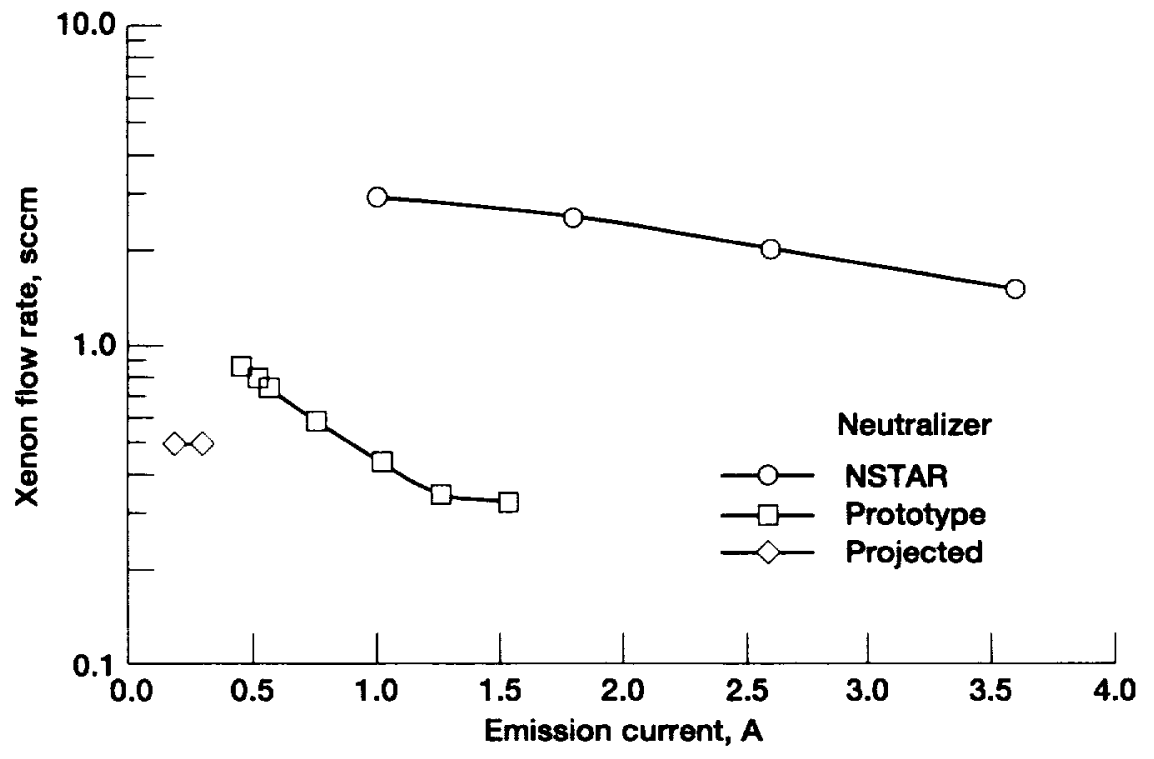

Figure 3.-Neutralizer minimum xenon flow rate versus emission current.

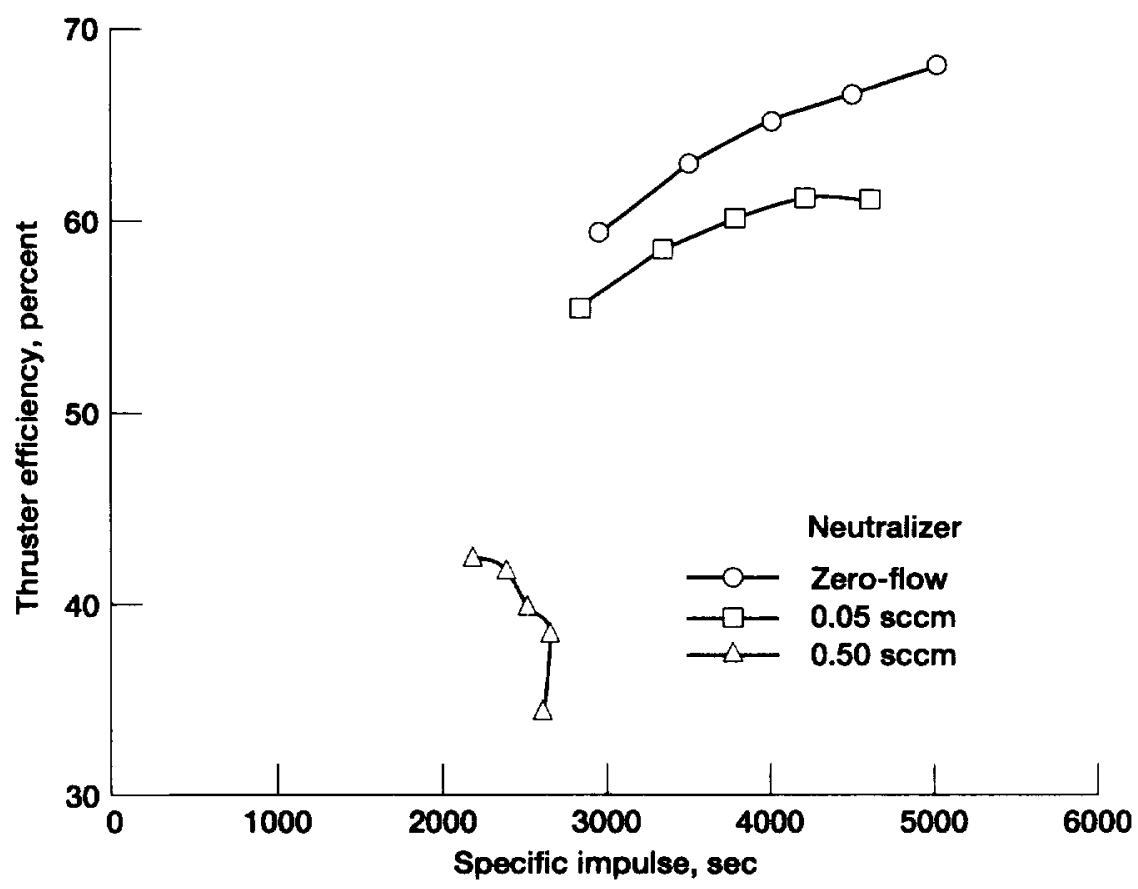

Figure 4.-Thruster efficiency versus specific impulse at $100 \mathrm{~W}$ input power; various neutralizers. 


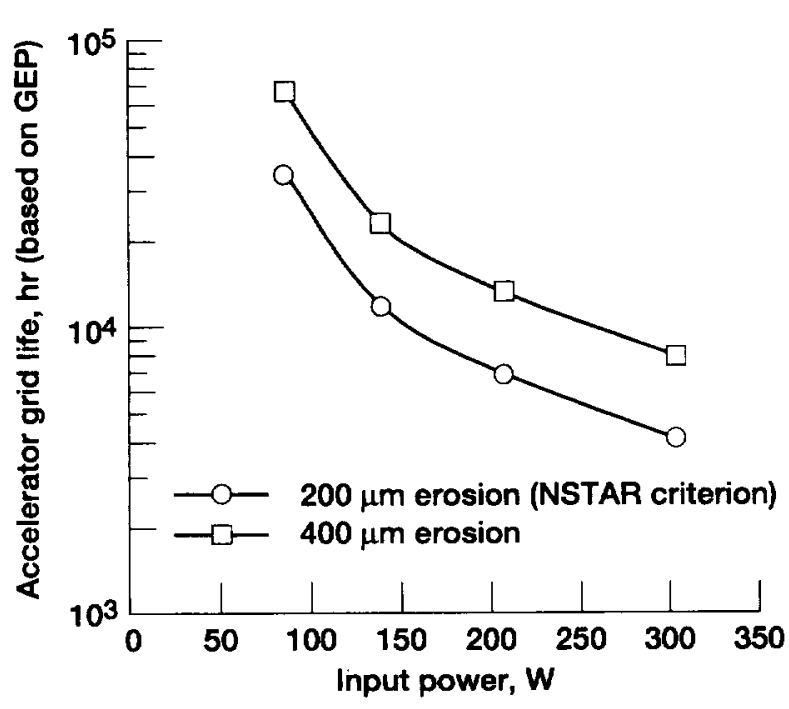

Figure 5.-Thruster life versus input power.

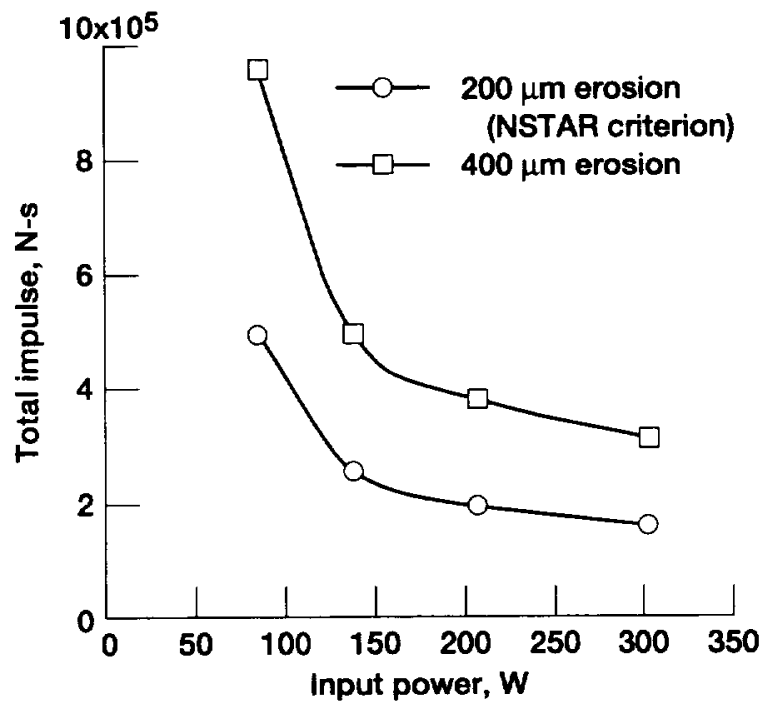

Figure 6.-Total impulse capability versus input power.

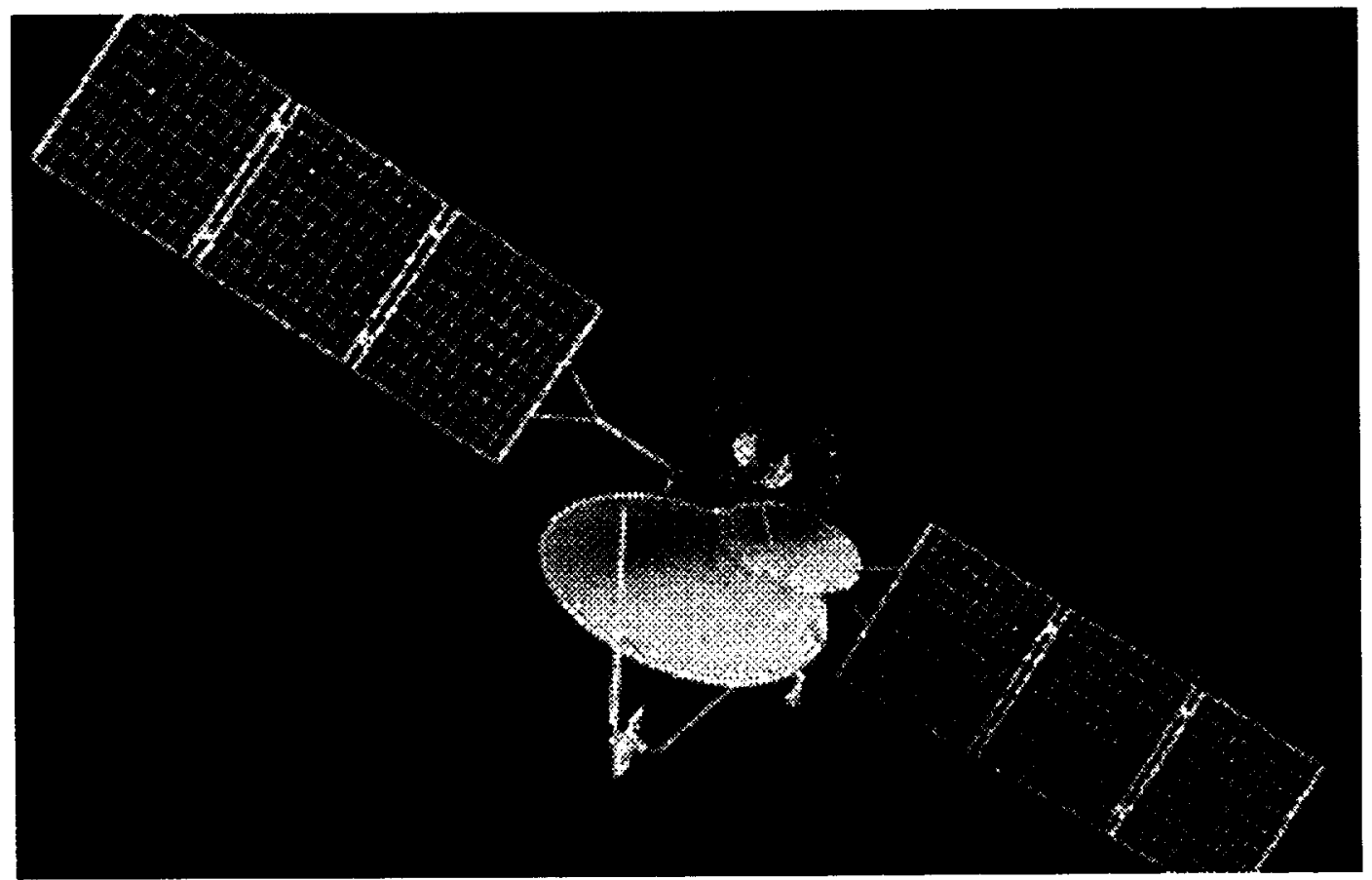

Figure 7.-IndoStar 1 spacecraft. 


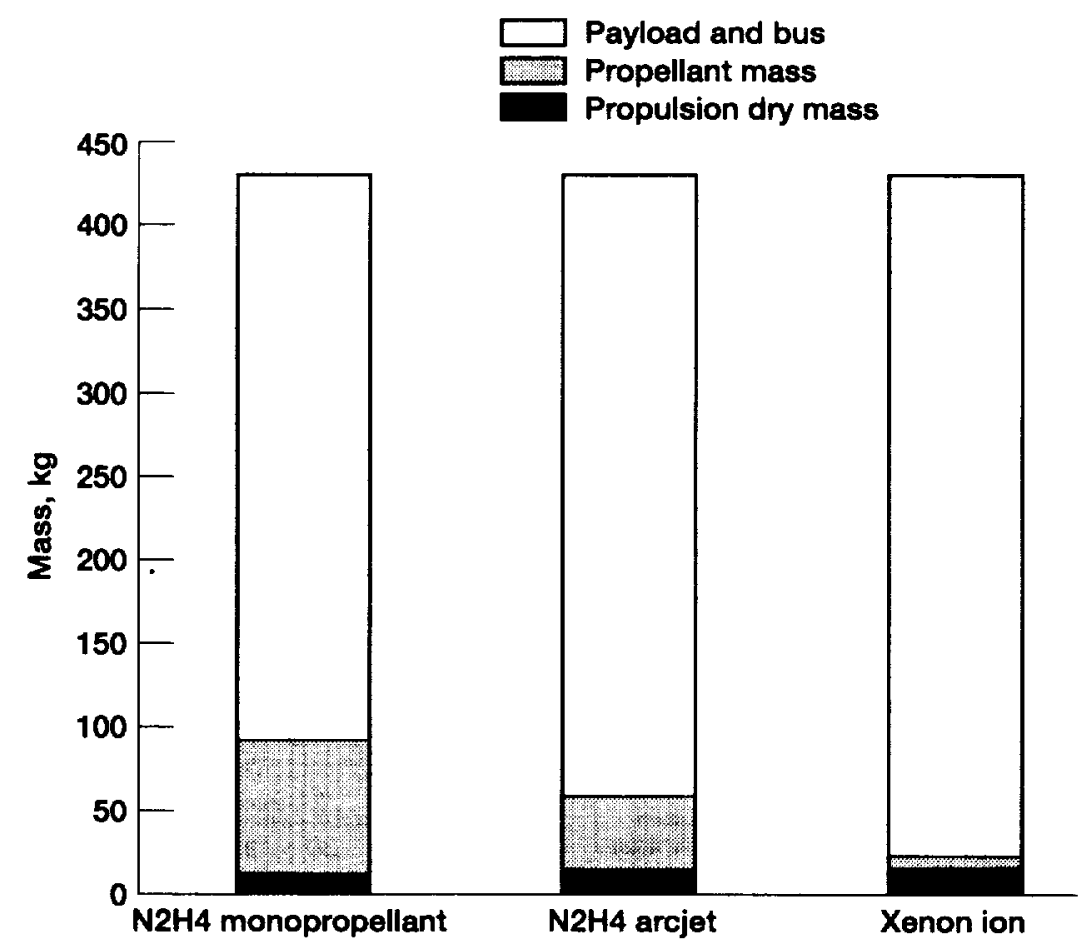

Figure 8.-Spacecraft mass comparison; geosynchronous mission.

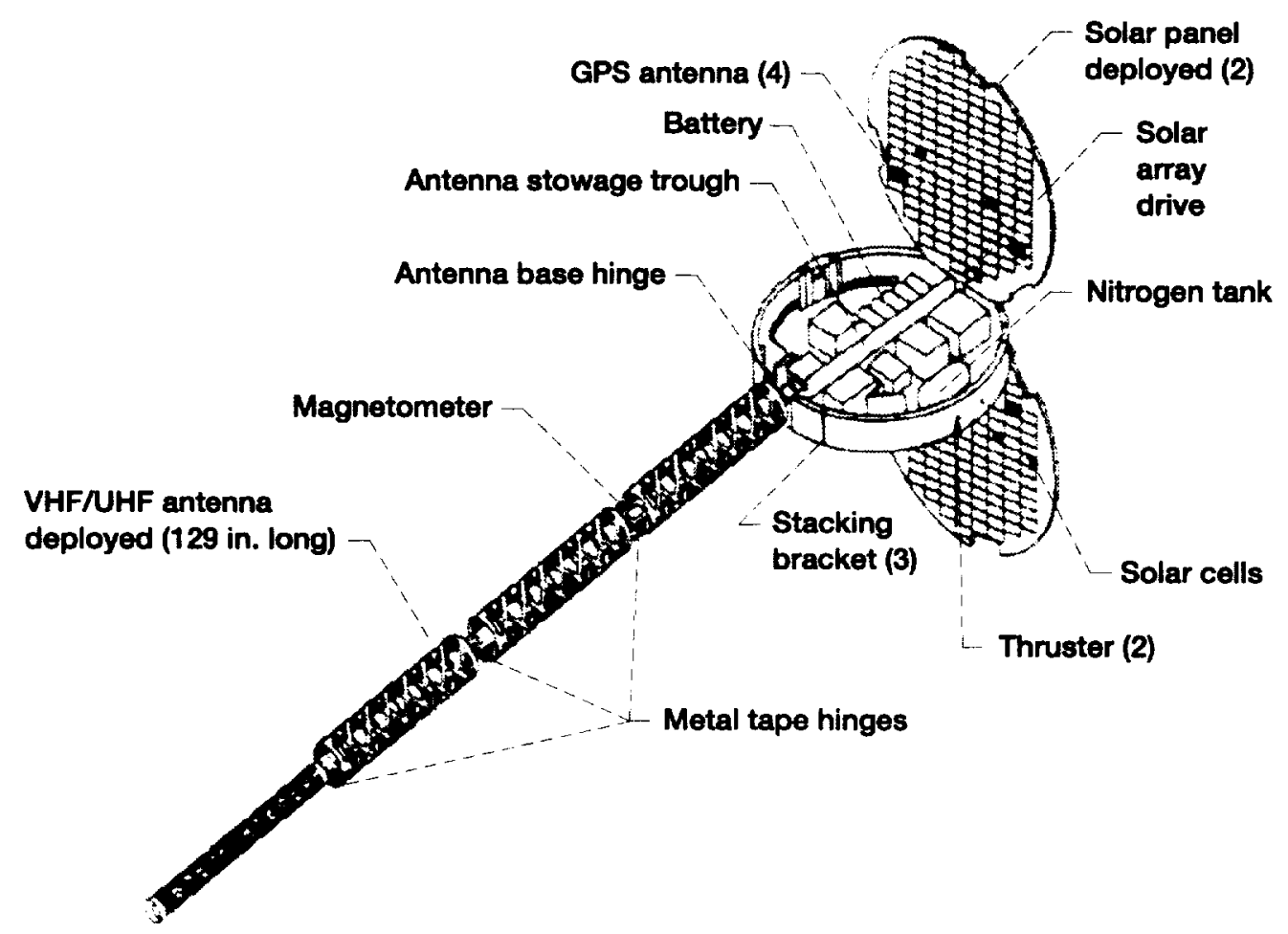

Figure 9.-Orbital Science Corporation's Microstar bus. 


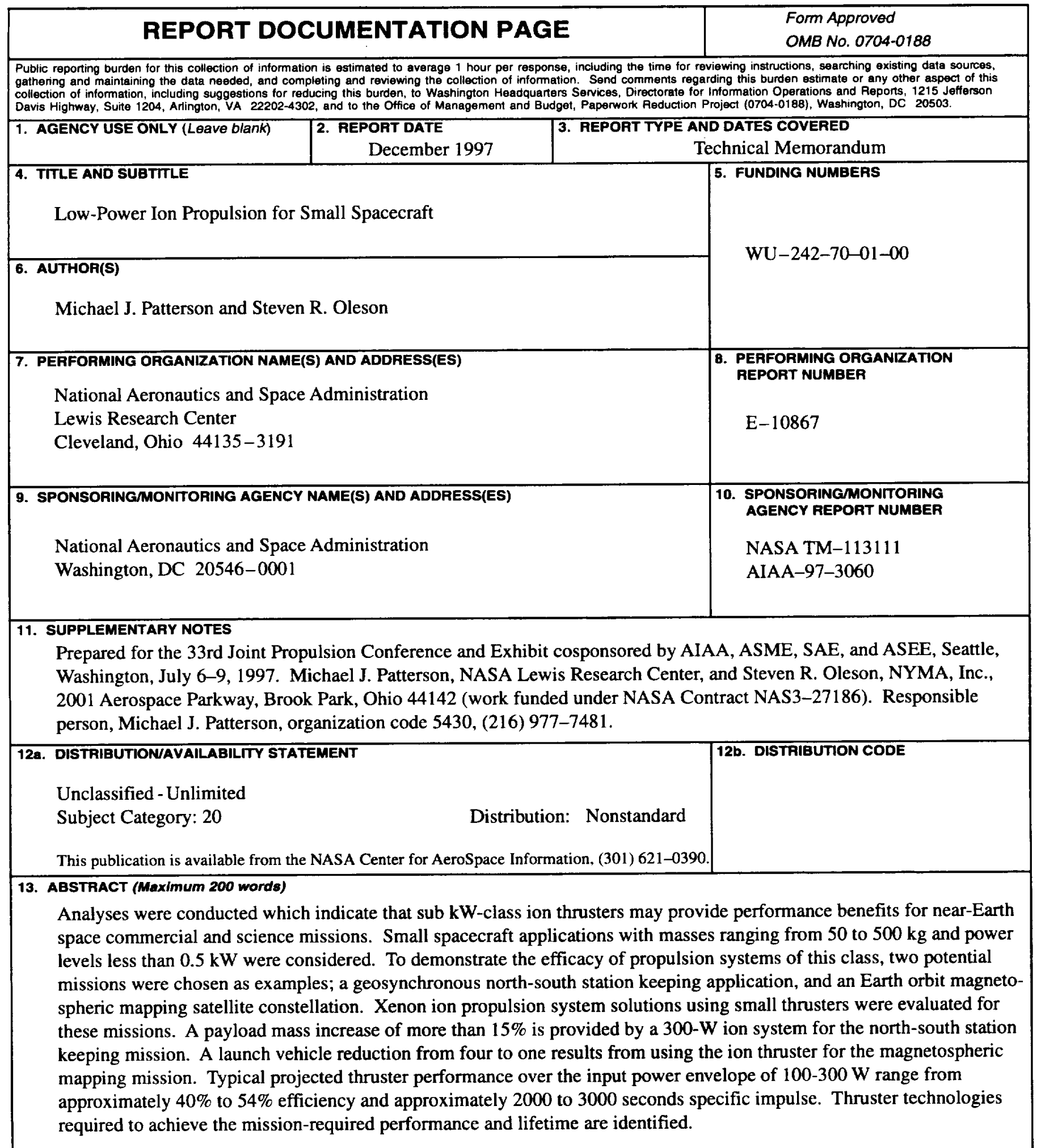

\begin{tabular}{|c|c|c|c|}
\hline 14. SUBJECT TERMS & & & 15. NUMBER OF PAGES \\
\hline \multicolumn{3}{|c|}{ Electric propulsion; Ion thruster } & \begin{tabular}{|c}
19 \\
16. PAICE CODE
\end{tabular} \\
\hline & & & A03 \\
\hline $\begin{array}{l}\text { 17. SECURITY CLASSIFICATION } \\
\text { OF REPORT }\end{array}$ & $\begin{array}{l}\text { 18. SECURTYY CLASSIFICATION } \\
\text { OF THIS PAGE }\end{array}$ & $\begin{array}{l}\text { 19. SECURITY CLASSIFICATION } \\
\text { OF ABSTRACT }\end{array}$ & 20. LIMITATION OF ABSTRACT \\
\hline Unclassified & Unclassified & Unclassified & \\
\hline
\end{tabular}




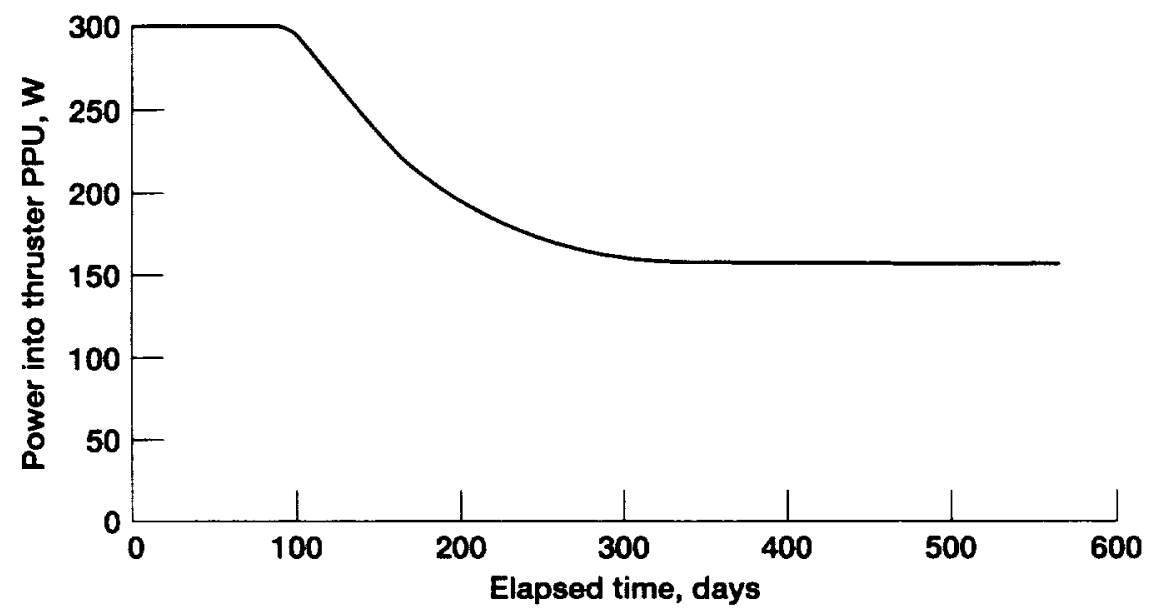

Figure 10.-Available power over mission; Magnetospheric Mapper.

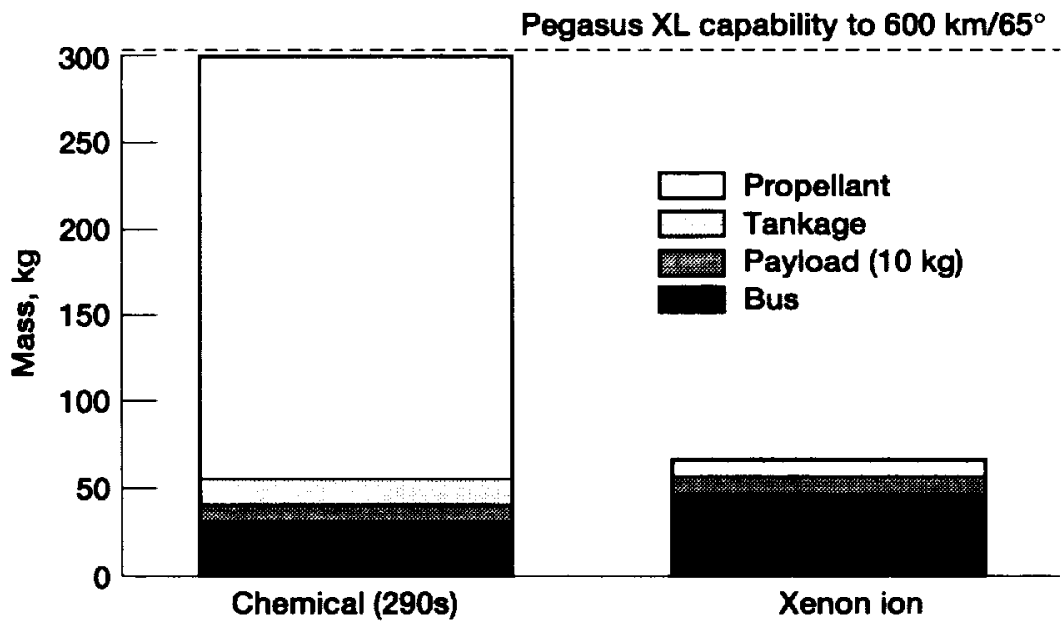

Figure 11.-Spacecraft mass comparison of magnetospheric mapping mission; chemical versus ion. 